\title{
Usefulness of electrophysiology in the prediction of outcome of Bell's palsy patients
}

\author{
Ibrahim Tharwat Abdelal ${ }^{1 *}$ D, Enas Abdelkader Eliwa' ${ }^{1}$, Amany Mohammad Ebaid ${ }^{1}$ and \\ Marwa Mohammad Abdelfattah ${ }^{2}$
}

\begin{abstract}
Background: Bell's palsy (BP) is a common idiopathic cranial mononeuropathy. The electrophysiological tests are one of supportive tools for localizing the site of facial nerve lesion, and to determine the severity and prognosis of the injury. The aim of this study was to evaluate the role of electrophysiology in the prediction of outcome of patients with Bell's palsy. This study was carried out on 30 adult patients with Bell's palsy. All study subjects were assessed clinically by Sunnybrook facial nerve grading score (SBS) and electrophysiologically by electroneurography (ENoG), blink reflex (BR), and electromyography (EMG); first evaluation was within 7th to10th day from onset, the second evaluation was done at 20th day, and the follow-up visit was after 1 month to assess the clinical grading system (SBS).
\end{abstract}

Results: At 1 month, 20 patients (66.7\%) had good recovery, while 10 patients (33.3\%) had poor recovery according to the Sunnybrook scale. Multiple logistic regression analysis showed that the most significant predictive indicator of BP recovery was ENoG value and R1 latency of BR test. The receiver operating characteristic (ROC) curves showed ENoG degeneration index of 74.6\%, considered as a critical cutoff value of non-recovery, with the sensitivity $95 \%$ and specificity 90\%, and the highest specificity was with blink reflex parameters (R1, R2 latency) 100\%.

Conclusion: BR and ENoG were the best predictors of non-recovery of facial function, while EMG findings did not add any prognostic significance. The combination of both tests $\mathrm{BR}$ and $\mathrm{ENOG}$, along with clinical findings can be considered a good indication in the acute phase of BP for the possibility to develop palsy residua.

Keywords: Bell's palsy, Sunnybrook scale, Electroneurography, Electromyography, Blink reflex

\section{Background}

The facial nerve is a mixed cranial nerve. It originates from its nucleus in the lower pons, a motor part that provides innervation of ipsilateral half of the facial expression muscles of the face, as well as the posterior belly of the digastric, the stapedius, and the stylohyoid muscles. The sensory and parasympathetic part of facial nerve are carried by fibers that constitute the nervus intermedius; sensory fibers derive taste sensation from anterior two-thirds of the tongue, and parasympathetic

\footnotetext{
*Correspondence: ibtharwat43@gmail.com

${ }^{1}$ Rheumatology \& Rehabilitation Department, Faculty of Medicine, Zagazig University, Zagazig, Egypt

Full list of author information is available at the end of the article
}

fibers serve to control the flow of saliva and tears from salivary and lacrimal glands. Finally, it emerges from the stylomastoid foramen before entering the parotid gland, where it bifurcates into upper and lower divisions and subsequently into 5 branches: temporal, zygomatic, buccal, marginal mandibular, and cervical [1].

Bell's palsy (BP) is acute idiopathic unilateral lower motor neuron facial nerve weakness or paralysis without any accompanying signs of neurologic or systemic manifestation [2]. It is a common idiopathic cranial mononeuropathy with annual incidence rate ranging between 13 and 53 cases per 100,000 of population [3]. In Egypt, $\mathrm{BP}$ has an incidence rate of (98.9-107)/100,000 of 
population, higher among male patients and peak age between 18 and 60 years, with low incidence at extremes of age [4].

The etiology of BP is still unknown and remains a diagnosis of exclusion. The etiological theories of Bell's palsy include the following: viral infection theory, autoimmune inflammatory disorder theory, vascular ischemic theory, and exposure to cold air draft [5].

The characteristic clinical findings are acute onset of unilateral lower motor neuron facial paralysis that affects muscles of the upper and lower face and its peak $72 \mathrm{~h}$, usually accompanied by neck pain, mastoid or ear, hyperacusis, or altered facial sensation. House-Brackmann (HB) scale [6] and Sunnybrook system (SBS) [7] are the most widely used clinical grading systems for recording the severity and monitoring outcomes of BP [8].

The electrophysiological tests are one of supportive tools for localizing the lesion site along the nerve, to determine the severity of the injury and differentiate whether an injured nerve is still degenerating or regenerating [9]. Electroneurography (ENoG), blink reflex (BR), and needle electromyography (EMG) are the most frequently used electrophysiological tests to determine BP prognosis, and they were studied but their predictive values were conflicting, and controversal [10].

The aim of this study was to evaluate the role of electrophysiology in the prediction of outcome of patients with Bell's palsy.

\section{Methods}

\section{Study design and subjects}

This study was performed at the electrophysiology unit of Rheumatology and Rehabilitation department, after review and approval by the Institutional Review Board. Thirty Bell's palsy patients aged from 19 to 54 years who visited rheumatology outpatient clinic during period of 6 months between April 2018 and October 2018 participated in this study.

Patients diagnosed as unilateral Bell's palsy at rheumatology outpatient clinic within first 10 days of onset and have enough physical and mental ability to understand the instructions and to cooperate throughout the session were included in study. All patients were receiving physiotherapy sessions, three times a week in the form of electrical stimulation and exercises for the facial muscles.

Patients with a previous history of peripheral facial paralysis, Ramsay Hunt syndrome, traumatic facial paralysis, central or peripheral nervous system disease other than idiopathic facial paralysis, facial palsy due to upper motor neuron lesions, or any known cause of the infection e.g., otitis media, autoimmune disease, e.g., sarcoidosis, diabetes mellitus, and presence of cardiac pacemaker were excluded.
Written informed consent was obtained from all participants and the study was approved by the research ethical committee. The work has been carried out in accordance with The Code of Ethics of the World Medical Association (Declaration of Helsinki) for studies involving humans.

\section{Clinical grading by Sunnybrook score}

Sunnybrook Facial Grading Scale (SBS) [7] ranges from 0 (complete paralysis) to 100 (normal facial function). The 3 sections of SBS are as follows: (1) resting posture, (2) voluntary movement, and (3) synkinesis. All are scored individually, and then the scores are combined for a total or composite score. The SBS score is calculated as follows: $\mathrm{SBS}=\mathrm{SBS}$ movement $-\mathrm{SBS}$ rest $-\mathrm{SBS}$ synkinesis. Patients with Bell's palsy seen within 1st 10 days of the onset (acute phase) were included in the study and the SBS was noted as baseline evaluation. The 2nd evaluation was done at 20th day and the 3rd evaluation was done after 1 month for follow-up.

\section{Electrophysiological studies}

The electrophysiological studies were performed within 7th-10th day of onset of the disease as a baseline evaluation using NIHON KOHDEN electrophysiological apparatus (neuropack X1). A second evaluation was done at 20th day and included the following:

\section{Electroneurography (ENoG)}

ENoG responses were measured on the affected and unaffected sides using bipolar surface stimulator placed over the stylomastoid foramen and recording from surface electrodes placed over the frontalis and mentalis muscles, increasing current intensity to evoke compound muscle action potential. The compound muscle action potential (CMAP) was obtained from the frontalis and mentalis muscles to measure amplitude degeneration ratio, then from nasalis muscle to measure degeneration index using this equation: [100 - (ENoG amplitude affected/unaffected side) $\times 100]$ [8] .

\section{Blink reflex (BR)}

BR was recorded at the supraorbital nerve with a bipolar surface stimulator electrode on both affected and unaffected sides, with the patient lying down in a quiet room with eyes open or gently closed. The evoked muscle action potentials (R1 and R2) were recorded for three consecutive times in each patient. Responses were defined as normal, delayed (R1 > $11.3 \mathrm{~ms} ; \mathrm{R} 2>33.9 \mathrm{~ms}$ ), or absent [10].

\section{Needle electromyography (EMG)}

EMG responses (at rest and during voluntary motion) were recorded with a concentric needle electrode using NIHON KOHDEN apparatus. The frontalis and mentalis 
muscles on the affected side were examined. EMG findings included degree of voluntary activity (maximum voluntary contraction, muscle reinnervation (presence/ absence of polyphasic motor unit potentials), and denervation (presence/absence of fibrillation potentials). Maximum voluntary contraction was recorded then classified into; (complete or partial interference pattern, single oscillatory pattern and no contraction) [11].

\section{Statistical methods}

All statistical analyses were performed using IBM SPSS Statistics, version 18. Data from neurophysiological assessments are presented as mean \pm standard deviation or median (interquartile range [IQR]), as appropriate. Comparisons between different Sunnybrook score of BP severity at baseline were investigated by the $\mathrm{W}$ : paired Wilcoxon. Relationship between variables of interest was investigated by Spearman rank correlation coefficient. Cutoff values of DI were investigated by means of receiver operating characteristic (ROC). Odds ratios (OR), their corresponding 95\% confidence intervals (95\% CIs), and $P$ values were computed using logistic regression analysis to evaluate the effect of possible prognostic indicators on recovery. All potential predictors were added in the model as independent variables. Results are presented as odds ratios (ORs) with 95\% confidence intervals (CIs). $P$ value $<0.05$ indicates a statistically significant difference.

\section{Results}

The demographic and clinical characteristics of the 30 studied patients are summarized in Table 1. It showed statistically highly significant increase in SBS with increased follow-up time $\left(P^{<} 0.001\right)$.

As regards electrophysiological data, the ENoG test showed difference in findings between the first and second assessments $(P<0.001)$ (Fig. 1). Degeneration index (DI) of nasalis was more than $90 \%$ in 4 cases (13.3\%) during baseline evaluation and in 3 cases (10\%) during 2nd evaluation $(P=0.004)$ (Fig. 2). Amplitude degeneration ratio of the frontalis was $>50 \%$ in 21 cases $(70 \%)$ during baseline evaluation and in 12 cases $(40 \%)$ during 2 nd evaluation $(P=0.01)$, while mentalis amplitude was $>50 \%$ in 27 cases (90\%) during baseline evaluation and in 10 (33.3\%) during 2nd evaluation $\left(P^{<} 0.001\right)$ (Fig. 3). All 30 patients had a recorded blink reflex. Six patients had normal R1 latency: 10 delayed and 14 absent R1 latency at 7th-10th day. Sixteen patients had normal R1 latency: 7 delayed and 7 still absent R1 latency at 20th day.

There was statistically significant difference in the latency values in the affected side in 2nd evaluation compared to 1st evaluation in both R1 (Fig. 4), R2 ipsilateral, and contralateral. Needle electromyography results showed significant difference between 1st and 2nd
Table 1 Demographic and clinical data of studied patients

\begin{tabular}{llll}
\hline Variable & $(n=30)$ & \\
\hline Age (year) & & \\
$\quad$ Mean \pm SD & $33.9 \pm 10.35$ & & \\
$\quad$ Range & $19-54$ & & \\
Variable & $n$ & $\%$ & \\
Sex & & 30 & \\
$\quad$ Male & 9 & 70 & \\
$\quad$ Female & 21 & & \\
Side & 12 & 40 & \\
$\quad$ Rt & 18 & 60 & \\
$\quad$ Lt & Median (range) & Fr & P \\
Variable & & & \\
SBS & $20(5-46)$ & 58.07 & \\
$\quad$ 1st evaluation (7th-10th day) & $44(7-77)$ & & \\
2nd evaluation(20 days) & $78(11-96)$ & & \\
$\quad$ Follow-up (30 days) &
\end{tabular}

Fr Friedman test, SBS Sunnybrook facial nerve grading score

${ }^{* *}$ Highly significant $(P<0.01)$

evaluation as regards presence of denervation (Fig. 5). There was statistically significant increase in SBS among patients having no denervation and patients having complete or partial interference at 1st evaluation; also, there was statistically significant increase in SBS among patients having no denervation, patients having reinnervation, and patients having complete or partial interference pattern at 2 nd evaluation. There was statistically significant increase in frequency of patients with DI $>75$ and patients with absent blink reflex among patients having denervation potential (Table 2). At 1 month, 20 patients $(66.7 \%)$ had good recovery, while 10 patients (33.3\%) had poor recovery according to the Sunnybrook scale. Table 3 summarizes the baseline electrophysiological data according to the clinical outcome at 1 month, no significant association between recovery and degeneration ratio of frontalis and mentalis. The facial nerve degeneration index recorded from nasalis was significantly lower in patients with good recovery compared with poor recovery patients $(P=0.002)$. All ten "not recovered" patients $(100 \%)$ were classified as absent R1 latency at baseline, while other 16 patients out of 20 patients that recorded normal or delayed $\mathrm{R} 1, \mathrm{R} 2 \mathrm{i}$, and R2c latency during baseline evaluation achieved complete recovery after 1 month (Table 3).

There was statistically highly significant increase in DI, presence of denervation, and absent R1 response among non-recovered patients after 1 month (Fig. 6). By studying validity of different parameters in prediction of patient improvement among the studied patients, frontalis amplitude and nasalis degeneration index have the highest sensitivity and accuracy, while 


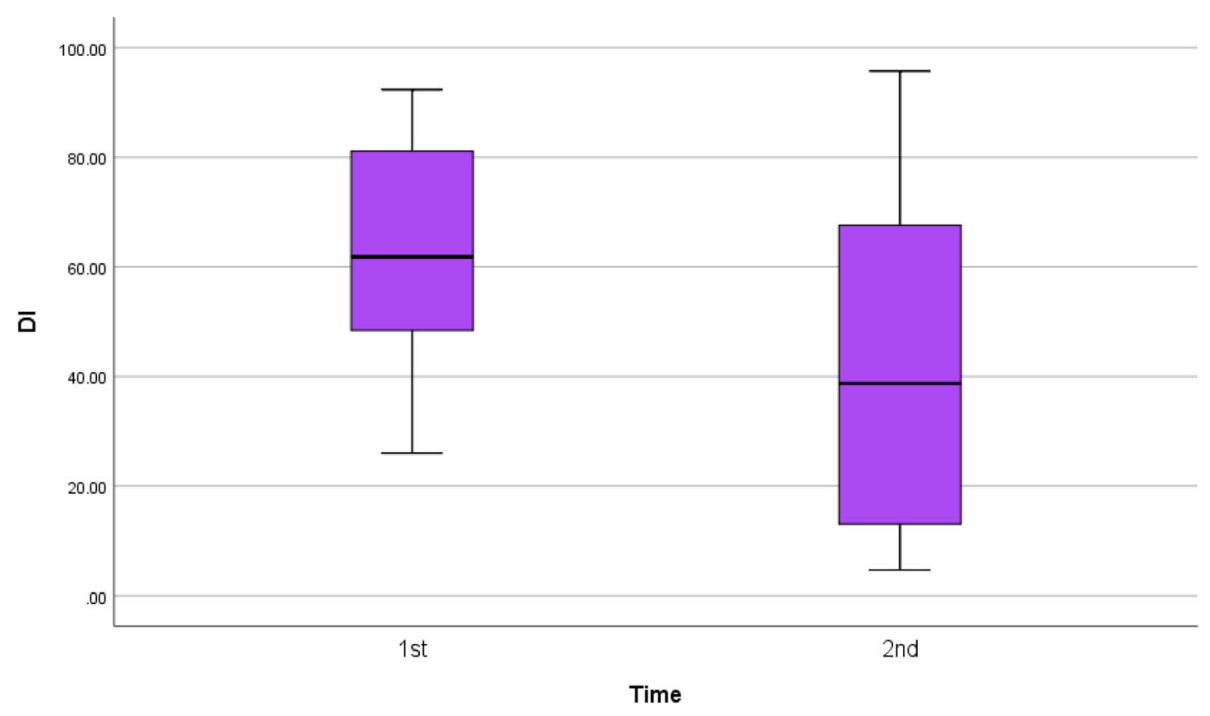

Fig. 1 Degeneration index of the affected side of nasalis among the studied patients

blink reflex parameters have the highest specificity (Table 4).

According to logistic regression analysis (Table 5), only the combination of BR and ENoG provided useful data in predicting those subjects who would not recover after facial paralysis $(\mathrm{OR}=3.78, P=0.002)(\mathrm{OR}=3.15$, $P=0.02)$ respectively.

\section{Discussion}

Approximately $70 \%$ of $\mathrm{BP}$ patients resolve completely with near normal function. The remainder resolves with residue as facial weakness, hemifacial spasm, synkinesis, or facial contracture. The treatment of BP includes drug therapy; corticosteroid, antiviral, and vitamin B12 supplementation; physical therapies; and surgical treatment [12].
Although electrical tests were already introduced in the 1970s [13], many controversial studies concerning the prognostic value of each of these tests have followed $[10,14,15]$. In our study, we evaluated the usefulness of ENoG, BR, and EMG in patients with Bell's palsy and correlated the findings of electrophysiological parameters with Sunnybrook facial nerve grading scale to predict the outcome at 1 month.

Our study included $30 \mathrm{BP}$ patients; their ages ranged from 19 to 54 years, with a mean of $33.9 \pm 10.35$ years. In 2002, Peitersen stated that the peak incidence of BP occurs between the 2nd and 4th decades (15 to 45 years) but the disease may occur at any age [16].

In our study, 21 patients were females (70\%) and 9 patients were males (30\%). Holland and Weiner [17] have reported that there was a slight female preponderance

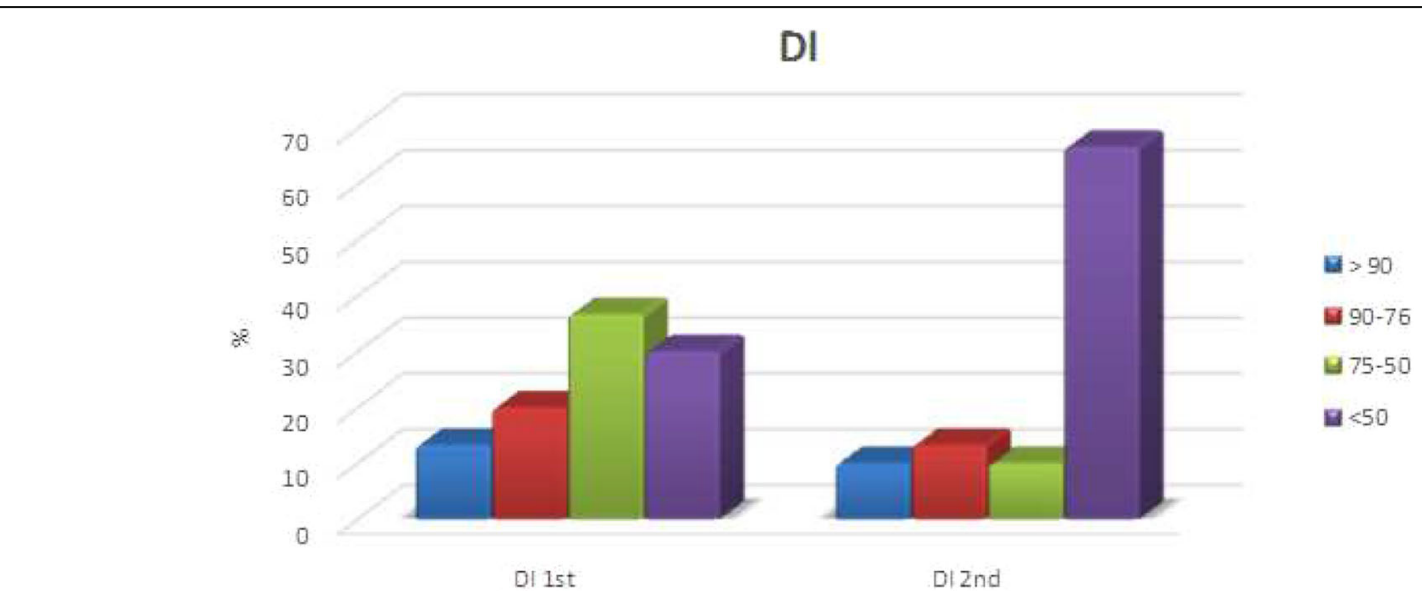

Fig. $2 \mathrm{Dl}$ among the studied patients at 1st and 2nd evaluation 
$\square<50 \quad \square 50$

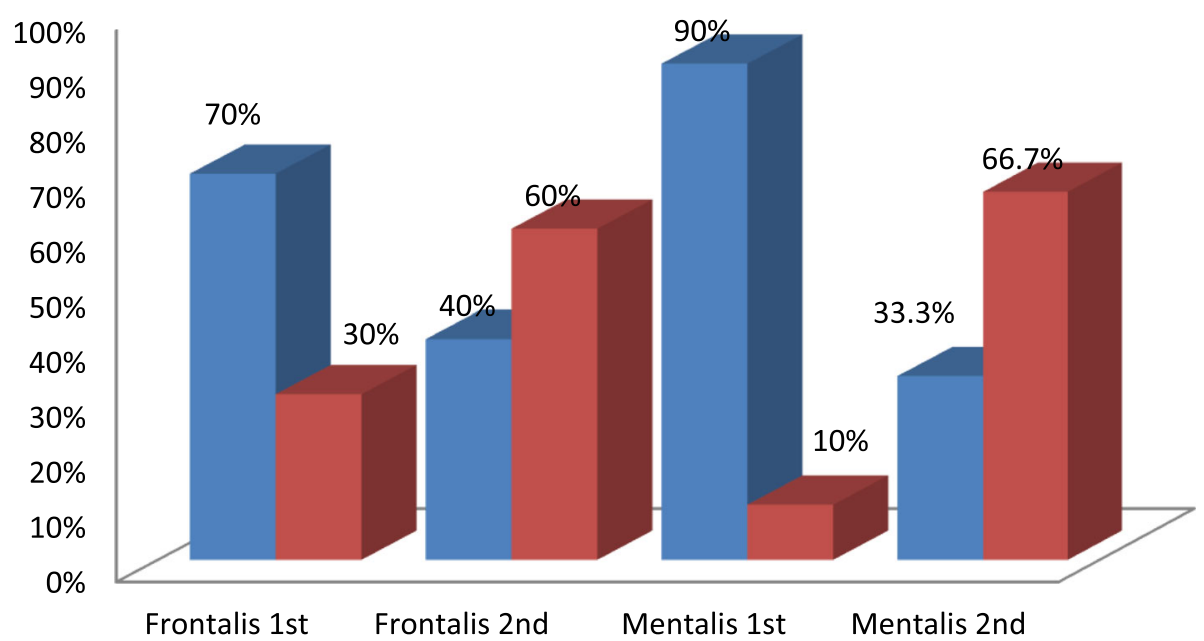

Fig. 3 Amplitude degeneration ratio of the frontalis and mentalis of the affected side

but both males and females were affected equally according to Peitersen study [16]. In contrast, Byun et al. recruited 66 patients diagnosed as $\mathrm{BP}$ and found a male preponderance in his studied patients. The ratio of male to female was (2:1); however, they did not find a correlation between the patient's sex and recovery [14].

In our study, eighteen patients (60\%) had left side affected, while twelve patients had the right side affected (40\%). This agreed with Cirpaciu et al. [15] who reported that left side was affected more than right side. In contrast, Byun et al. [14] found a rightside predilection. However, in all studies, there was no association between side of facial palsy and complete recovery.
There was statistically significant difference between the serial SBS grades across the successive visits indicating clinical improvement of the patients. In our study, 20 patients $(66.7 \%)$ had good prognosis according to SBS achieving score $\geq 70$ and 10 patients (33.3\%) had bad prognosis (SBS < 70) based on the SBS at the end of 1 month. This result was consistent with those of Prakash and Raymond, who found that one-third of the total number of patients recovered completely within 1 month and about 70\% recovered within 2 months after the onset of Bell's palsy [18].

In comparing amplitude of the CMAP of the affected side with the unaffected side, we found 21 patients $(70 \%)$ of frontalis and 27 patients (90\%) of mentalis recorded

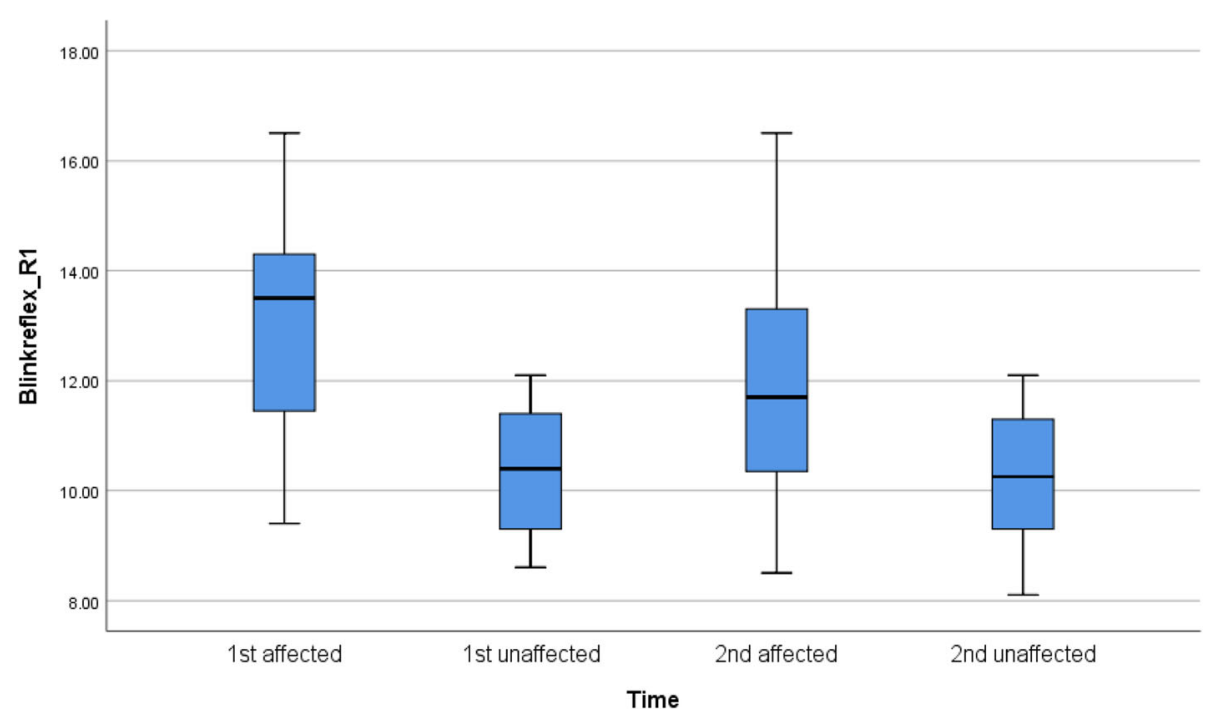

Fig. 4 R1 among the studied patients at 1st and 2nd evaluation 


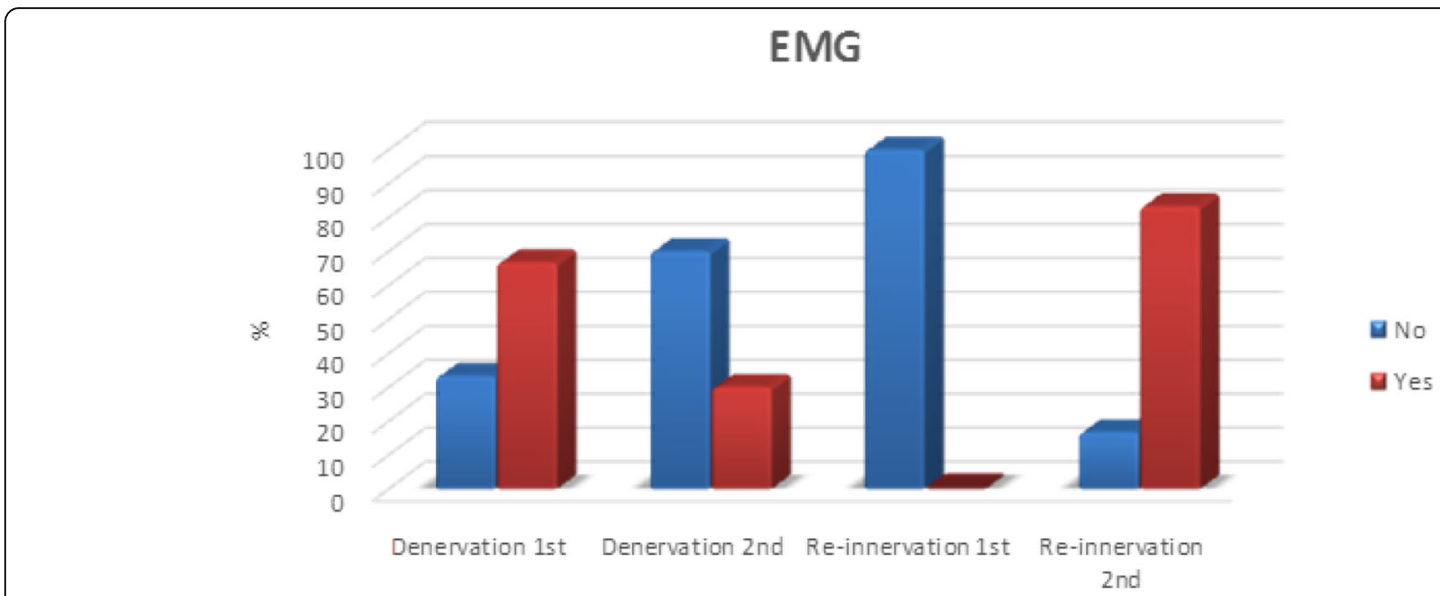

Fig. 5 EMG among the studied patients at 1st and 2nd evaluation

degeneration ratio $>50$ during 1st evaluation, while 10 patients (33.3\%) of frontalis and 12 patients (40\%) of mentalis during 2nd evaluation. One hundred percent of non-recovered patient have degeneration ratio $>50 \%$ of mentalis and $90 \%$ of non-recovered patient have degeneration ratio $>50 \%$ of frontalis. The findings in the present study are consistent with those of Danielidis et al., who reported that when the CMAP decreased to a value below $51 \%$ of normal values (more than 50\% degeneration ratio), prognosis for recovery was considerably worse due to more severe axon degeneration [19].

Our findings agreed with a study done by Khedr et al., who assessed degeneration rate in the frontalis and orbicularis muscles conducted on 59 patients with BP using cutoff value of $50 \%$ then assess poor recovery at 3rd month and found that patients who had a facial nerve degeneration ratio $<50 \%$ (38 cases) had a higher percent of good recovery [20].

Table 2 Relation between the patterns of abnormal rest potentials detected by needle EMG with the different electrophysiological tests

\begin{tabular}{|c|c|c|c|c|c|c|}
\hline \multirow[t]{2}{*}{ Variable } & \multicolumn{2}{|c|}{ Absence of denervation $(n=10)$} & \multicolumn{2}{|c|}{ Presence of denervation $(n=20)$} & \multirow[t]{2}{*}{$x^{2}$} & \multirow[t]{2}{*}{$P$} \\
\hline & No. & $\%$ & No. & $\%$ & & \\
\hline \multicolumn{7}{|l|}{$\mathrm{DI}$} \\
\hline$>90$ & 0 & 0 & 4 & 20 & \multirow[t]{4}{*}{9.55} & \multirow[t]{4}{*}{$0.02^{*}$} \\
\hline $90-76$ & 0 & 0 & 7 & 35 & & \\
\hline $75-50$ & 4 & 40 & 6 & 30 & & \\
\hline$<50$ & 6 & 60 & 3 & 15 & & \\
\hline \multicolumn{7}{|c|}{ R1 latency (ms) } \\
\hline Normal & 5 & 50 & 1 & 5 & \multirow[t]{3}{*}{15} & \multirow[t]{3}{*}{$0.001 * *$} \\
\hline Delayed & 5 & 50 & 5 & 25 & & \\
\hline Absent & 0 & 0 & 14 & 70 & & \\
\hline \multicolumn{7}{|c|}{ R2-ipsilateral latency (ms) } \\
\hline Normal & 6 & 60 & 2 & 10 & \multirow[t]{3}{*}{14.25} & \multirow[t]{3}{*}{$0.001^{* *}$} \\
\hline Delayed & 4 & 40 & 4 & 20 & & \\
\hline Absent & 0 & 0 & 14 & 70 & & \\
\hline \multicolumn{7}{|c|}{ R2-contralateral latency (ms) } \\
\hline Normal & 6 & 60 & 2 & 10 & \multirow[t]{3}{*}{14.25} & \multirow[t]{3}{*}{$0.001^{* *}$} \\
\hline Delayed & 4 & 40 & 4 & 20 & & \\
\hline Absent & 0 & 0 & 14 & 70 & & \\
\hline
\end{tabular}

EMG electromyography, DI degeneration index 
Table 3 Relationship between electrophysiological data and recovery at 1 month according to Sunnybrook score (SBS)

\begin{tabular}{|c|c|c|c|c|c|c|}
\hline \multirow[t]{2}{*}{ Variable } & \multicolumn{2}{|c|}{ Recovered SBS $\geq 70(n=20)$} & \multicolumn{2}{|c|}{ Not recovered SBS < $70(n=10)$} & \multirow[t]{2}{*}{$x^{2}$} & \multirow[t]{2}{*}{$P$} \\
\hline & $\bar{N}$ & $\%$ & $\bar{N}$ & $\%$ & & \\
\hline \multicolumn{7}{|l|}{ Frontalis amplitude ratio } \\
\hline$>50$ & 12 & 60 & 9 & 90 & \multirow[t]{2}{*}{2.86} & \multirow[t]{2}{*}{$0.09 \mathrm{NS}$} \\
\hline$\leq 50$ & 8 & 40 & 1 & 10 & & \\
\hline \multicolumn{7}{|l|}{ Mentalis amplitude ratio } \\
\hline$>50$ & 17 & 85 & 10 & 100 & \multirow[t]{2}{*}{1.67} & \multirow[t]{2}{*}{$0.20 \mathrm{NS}$} \\
\hline$\leq 50$ & 3 & 15 & 0 & 0 & & \\
\hline \multicolumn{7}{|l|}{ DI of nasalis } \\
\hline$>90$ & 0 & 0 & 4 & 40 & \multirow[t]{2}{*}{9.23} & \multirow[t]{2}{*}{$0.002^{* *}$} \\
\hline$\leq 90$ & 20 & 100 & 6 & 60 & & \\
\hline \multicolumn{7}{|l|}{ Denervation } \\
\hline No & 10 & 50 & 0 & 0 & \multirow[t]{2}{*}{7.5} & \multirow[t]{2}{*}{$0.006^{* *}$} \\
\hline Yes & 10 & 50 & 10 & 100 & & \\
\hline \multicolumn{7}{|l|}{ Reinnervation } \\
\hline No & 20 & 100 & 10 & 100 & \multirow[t]{2}{*}{-} & \multirow[t]{2}{*}{-} \\
\hline Yes & 0 & 0 & 0 & 0 & & \\
\hline \multicolumn{7}{|l|}{ Interference pattern } \\
\hline Complete and partial & 15 & 75 & 2 & 20 & \multirow[t]{3}{*}{15.63} & \multirow[t]{3}{*}{$<0.001^{* *}$} \\
\hline Single oscillation & 5 & 25 & 2 & 20 & & \\
\hline No contraction & 0 & 0 & 6 & 60 & & \\
\hline \multicolumn{7}{|l|}{ R1 latency (ms) } \\
\hline Normal & 6 & 30 & 0 & 0 & \multirow[t]{3}{*}{17.14} & \multirow[t]{3}{*}{$<0.001^{* *}$} \\
\hline Delayed & 10 & 50 & 0 & 0 & & \\
\hline Absent & 4 & 20 & 10 & 100 & & \\
\hline \multicolumn{7}{|l|}{ R2-ipsilateral latency (ms) } \\
\hline Normal & 8 & 40 & 0 & 0 & \multirow[t]{3}{*}{17.15} & \multirow[t]{3}{*}{$<0.001^{* *}$} \\
\hline Delayed & 8 & 40 & 0 & 0 & & \\
\hline Absent & 4 & 20 & 10 & 100 & & \\
\hline R2-contralateral latency & & & & & & \\
\hline Normal & 8 & 40 & 0 & 0 & 17.15 & $<0.001^{* *}$ \\
\hline Delayed & 8 & 40 & 0 & 0 & & \\
\hline Absent & 4 & 20 & 10 & 100 & & \\
\hline
\end{tabular}

SBS Sunnybrook facial nerve grading score, $D /$ degeneration index

We found that four patients $(10 \%)$ with DI were $>90$ during 1 st evaluation, while only three patients $(10 \%)$ were $>90$ during 2 nd evaluation. All patients who later showed a complete recovery after 1 month gave $\mathrm{DI}<$ $90 \%$ at baseline evaluation; however, there were 6 patients (20\%) gave $\mathrm{DI}<90 \%$ and classified as nonrecovery patients.

Our results were consistent with the observations of Mantsopoulos et al., who found that not all of subjects with DI $<90 \%$ showed complete recovery [21]. As opposed to these findings, Linder et al. and Sittel et al. found that a high percentage of BP subjects spontaneously improves within 1 year of onset $[11,22]$. This difference can be explained by the difference of etiology and degree of the palsy, ENoG cutoff value, initial timing for evaluation, and prognostic follow-up time which may be shorter in our study in comparison with other studies.

Our results showed that all "non recovered" patients with apparently severe palsy (100\%) were classified as absent R1 response at baseline, while other patients that recorded normal or delayed R1, R2i, and R2c latency during baseline evaluation achieved complete recovery after 1 month.

Our results were consistent with the observations of Mancini et al., who recorded the blink reflex from severe grades of $95 \mathrm{BP}$ patients and found that R1component 


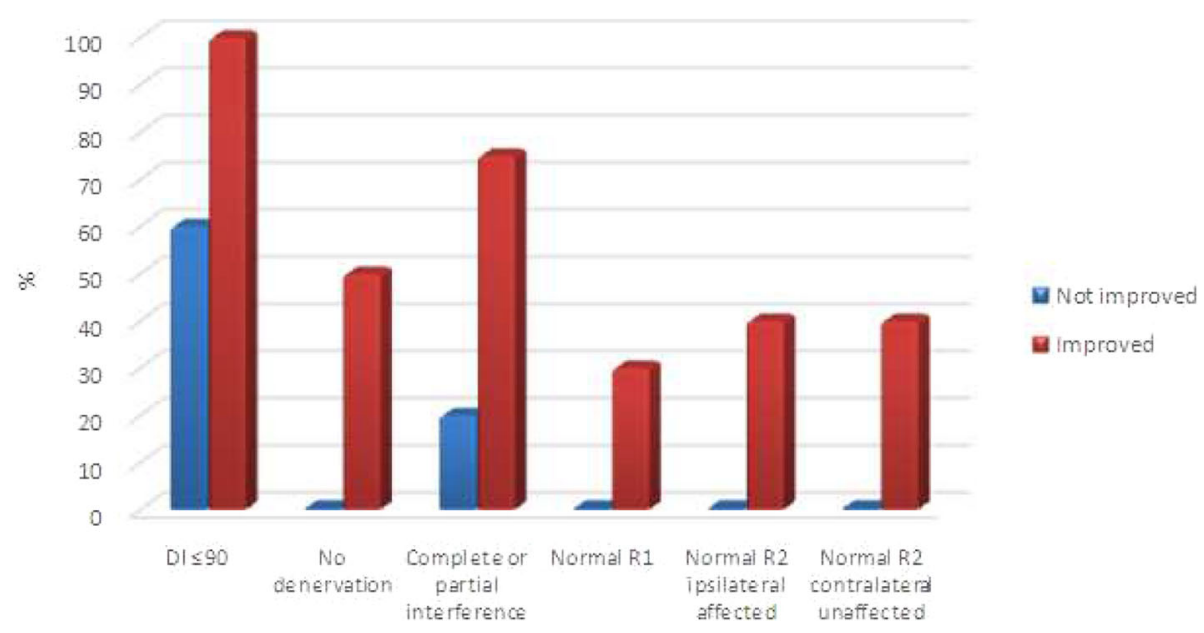

Fig. 6 Relation between SBS at follow-up visit (30th day) and different parameters of the studied patients

was present in 40\% (normal or delayed) and absent in $60 \%$ of patients when tested at the 7 th-10th day. On retesting at 20th day, the reflex had recorded in 68\% (normal or delayed) and still absent in $32 \%$ of patients [10]. The severity of degree of BP patients in Mancini et al., study can explain the cause of large percent in absent R1 when comparing with our results.

Our findings were consistent with Heath et al., who found that all patients had a complete recovery or a satisfactory recovery at 1 month had normally or delayed R1component [23].

During the first EMG examination, 10 out of the 20 "recovered" patients $(50 \%)$ having denervation potentials had a good prognosis and achieved complete recovery by the lapse of 1 month. Ten patients out of the 30 patients with denervation potentials had a poor prognosis after1 month. Presence of reinnervation potential during minimal volition was present in $100 \%$ of the recovered patients.

The validity of different electrophysiological tests was analyzed, and we found that cutoff $75 \%$ degeneration index was the best predictor for non-recovery at baseline according to ROC curve. The test had 95\% sensitivity, $93.3 \%$ accuracy, and $90 \%$ specificity predicting the outcome, although DI showed lower specificity and sensitivity when compared to studies that focus on severe grades [24-26].

The blink reflex recorded (100\% PPV). The test had $80 \%$ sensitivity, $86.7 \%$ accuracy, and $100 \%$ specificity for prediction of BP outcome. Mikula et al. reported similar results in their study, with a specificity and sensitivity of BR at 5-7 days post-onset higher than other tests and increases with time. BR shows an accuracy of $90 \%$ in predicting residual motor deficit providing early and reliable information on the degree of axonal block when assessed in the acute and sub-acute phases [27].

According to logistic regression analysis, the best predictive indicator of poor recovery was a combination of electroneurography and blink reflex tests. This was consistent with studies that analyzed prognostic factors in 92 patients [10] and 98 patients [28] with BP and reported that the combination of BR test and ENoG results was the best predictor of residual palsy. We observed similar results in our study with non-recovery rate being significantly higher in BP patients with BR absent response and low mean ENoG.

Table 4 Validity of different parameters in prediction of patient improvement among the studied patients

\begin{tabular}{|c|c|c|c|c|c|c|c|c|c|}
\hline Variable. & Cutoff & AUC & $\mathrm{Cl}$ & $P$ & Sensitivity & Specificity & PPV & NPV & Accuracy \\
\hline SBS 1st & $>13.5$ & 0.92 & $0.83-1$ & $<0.001^{* *}$ & 85 & 90 & 94.4 & 75 & 86.7 \\
\hline Frontalis & $>795$ & 0.91 & $0.74-1$ & $<0.001^{* *}$ & 95 & 90 & 95 & 90 & 93.3 \\
\hline Mentalis & $>820$ & 0.95 & $0.86-1$ & $<0.001^{* *}$ & 90 & 80 & 90 & 80 & 86.7 \\
\hline DI & $74.67 \%$ & 0.90 & $0.73-1$ & $<0.001^{* *}$ & 95 & 90 & 95 & 90 & 93.3 \\
\hline R1 latency & 11.5 & 0.90 & $0.79-1$ & $<0.001^{* *}$ & 80 & 100 & 100 & 71.4 & 86.7 \\
\hline R2 ipsilateral & 39.2 & 0.90 & $0.79-1$ & $<0.001^{* *}$ & 80 & 100 & 100 & 71.4 & 86.7 \\
\hline R2 contralateral (unaffected) & 39 & 0.90 & 0.79-1 & $<0.001^{* *}$ & 80 & 100 & 100 & 71.4 & 86.7 \\
\hline
\end{tabular}

SBS Sunnybrook facial nerve grading score, $D /$ degeneration index 
Table $\mathbf{5}$ Logistic regression analysis for significant predictors for Bell's palsy recovery

\begin{tabular}{|c|c|c|c|c|c|c|c|}
\hline \multirow[t]{2}{*}{ Variable } & \multirow[t]{2}{*}{ B } & \multirow[t]{2}{*}{ S.E. } & \multirow[t]{2}{*}{ Wald } & \multirow[t]{2}{*}{ Sig. } & \multirow[t]{2}{*}{ OR } & \multicolumn{2}{|l|}{$95 \% \mathrm{Cl}$} \\
\hline & & & & & & Lower & Upper \\
\hline SBS 1st > 13.5 & 0.14 & 0.25 & 1.01 & 0.32 & 2.01 & 0.92 & 2.5 \\
\hline Frontalis degeneration ratio $<50$ & 0.08 & 0.12 & 0.98 & 0.29 & 1.02 & 0.83 & 2.01 \\
\hline Mentalis degeneration ratio $<50$ & -0.02 & 0.03 & 0.78 & 0.38 & 0.98 & 0.93 & 1.03 \\
\hline Absent R1 & 1.15 & 0.63 & 3.02 & $0.002^{* *}$ & 3.78 & 2.05 & 7.84 \\
\hline Absent R2 ipsilateral (affected) & 0.16 & 0.23 & 1.04 & 0.30 & 1.98 & 0.90 & 2.22 \\
\hline Absent R2 contralateral (unaffected) & 0.10 & 0.18 & 0.95 & 0.49 & 1.0 & 0.85 & 2.34 \\
\hline $\mathrm{DI}>90$ & 1.23 & 0.42 & 2.98 & $0.02^{*}$ & 3.15 & 1.98 & 4.54 \\
\hline No denervation & 0.34 & 0.31 & 1.39 & 0.11 & 1.92 & 0.89 & 2.16 \\
\hline Reinnervation & 0.09 & 0.10 & 1.28 & 0.08 & 1.5 & 0.76 & 2.65 \\
\hline Complete or partial interference & 0.19 & 0.19 & 0.93 & 0.84 & 1.65 & 0.76 & 1.99 \\
\hline
\end{tabular}

SBS Sunnybrook facial nerve grading score, $D /$ degeneration index, $O R$ odds ratio

Limitations of this study included small sample size and short period of follow-up for patient recovery. Despite this limitation, this study could support the importance of electrophysiological tests in the prediction of the recovery of Bell's palsy patients. Further studies focusing on large number of patients and longer follow-up are needed to verify the accuracy on a long-term basis.

\section{Conclusion}

The electrophysiological tests studied in the first 10 days after onset were helpful for the prediction of prognosis at 1 month. BR and ENoG were the best predictors of facial function non-recovery; EMG findings did not add any prognostic significance. Both BR and ENoG procedures significantly correlated with the severity of facial paralysis both at baseline and second evaluations, and the combination of both tests better explores the conduction along the entire length of the facial nerve.

\section{Abbreviations}

BP: Bell's palsy; BR: Blink reflex; Cl: Confidence interval; CMAP: Compound muscle action potential; DI: Degeneration index; EMG: Electromyography; ENoG: Electroneurography; HB: House-Brackmann scale; OR: Odds ratio; ROC: Receiver operating characteristics; SBS: Sunnybrook facial nerve grading score

\section{Acknowledgements}

We are very thankful to all our study participants and colleagues.

\section{Authors' contributions}

1- IT analyzed and interpreted the patient data, prepared, and revised the manuscript. 2- EE examined the patients by electrophysiological tests. She revised the results and approved he final manuscript. 3- AE revised the study methods and materials and collected the relevant study papers. 4- MM collected the patient history and samples and the required software. All authors read and approved the final submitted manuscript.

\section{Funding}

No

\section{Availability of data and materials}

The datasets used and/or analyzed during the current study are available from the corresponding author on reasonable request.

\section{Ethics approval and consent to participate}

The study was approved by the Institutional Review Board (IRB) Committee of Faculty of Medicine, Zagazig University. Written informed consent was obtained from all participants and the study was approved by the research ethical committee of Faculty of Medicine, Zagazig University. The work has been carried out in accordance with The Code of Ethics of the World Medical Association (Declaration of Helsinki) for studies involving humans. Reference number is not available (asked from my faculty IRB department, delay is due to corona disruption)

\section{Consent for publication}

All participants agreed to submit this manuscript in your journal for publication.

\section{Competing interests \\ No}

\section{Author details}

${ }^{1}$ Rheumatology \& Rehabilitation Department, Faculty of Medicine, Zagazig University, Zagazig, Egypt. ${ }^{2}$ Rheumatology and Rehabilitation, Fakous Hospital, Zagazig, Egypt.

Received: 9 April 2020 Accepted: 7 June 2020

Published online: 15 October 2020

References

1. Ho M, Juliano A, Eisenberg L, Moonis G (2015) Anatomy and pathology of the facial nerve. Am J Roentgenol 204(6):W612-W619

2. Reich S (2017) Bell's palsy, continuum (Minneap Minn). Selected Top Outpatient Neurol:447-466

3. Monini S, Lazzarino Al, lacolucci C, Buffoni A, Barbara M (2010) Epidemiology of Bell's palsy in an Italian Health District: incidence and casecontrol study. Acta Otorhinolaryngol Ital 30(4):198

4. El-Tallawy H, Farghaly W, Shehata G, Badri R, Hassan M, Hamed M et al (2016) Incidence and clinical predictors of outcome of Bell's palsy, Al-Quseir City, Red Sea governorate, Egypt, the Egyptian journal of neurology. Psychiatry Neurosurg 53(2):70-73

5. Glass G, Tzafetta K (2014) Bell's palsy: a summary of current evidence and referral algorithm. Fam Pract 31(6):631-642

6. House J, Brackmann D (1985) Facial nerve grading system. Otolaryngol Head Neck Surg 93:146-147

7. Ross B, Fradet G, Nedzelski J (1996) Development of a sensitive clinical facial grading system. Otolaryngol Head Neck Surg 114:380-386

8. Eviston T, Croxson G, Kennedy P, Hadlock T, Krishnan AV (2015) Bell's palsy: aetiology, clinical features and multidisciplinary care. J Neurol Neurosurg Psychiatry 86(12):1356-1361

9. Lee D (2016) Clinical efficacy of electroneurography in acute facial paralysis. J Audiol Otol 20(1):8-12 
10. Mancini P, De Seta D, Prosperini L, Nicastri M, Gabriele M, Ceccanti M et al (2014) Prognostic factors of Bell's palsy: multivariate analysis of electrophysiological findings. Laryngoscope 124:2598-2605

11. Sittel C, Stennert E (2001) Prognostic value of electromyography in acute peripheral facial nerve palsy. Otol Neurotol 22:100-104

12. Somasundara D, Sullivan F (2017) Management of Bell's palsy. Aust Prescr 40(3):94-97

13. Esslen E Electrodiagnosis of facial palsy. In: Miehlke A (ed) Surgery of the Facial Nerve1973. W.B. Saunders, Philadelphia, pp 45-51

14. Byun H, Cho YS, Jang JY, Chung KW, Hwang S, Chung WH et al (2013) Value of electroneurography as a prognostic indicator for recovery in acute severe inflammatory facial paralysis: a prospective study of Bell's palsy and Ramsay hunt syndrome. Laryngoscope 123(10):2526-2532

15. Cirpaciu D, Goanta C, Cirpaciu M (2014) Recurrences of Bell's palsy. J Med Life 7(3):68-77

16. Peitersen E (2002) Bell's palsy: the spontaneous course of 2,500 peripheral facial nerve palsies of different etiologies. Acta Otolaryngol Suppl 549:4-30

17. Holland N, Bernstein J. Bell's palsy. BMJ Clin Evid. 2014;2014:1204.

18. Prakash K, Raymond A (2003) The use of nerve conduction studiesin determining the short-term outcome of Bell's palsy. Med J Malaysia 58:69-78

19. Danielidis V, Skevas A, Van Cauwenberge P, Vinck B (1999) A comparative study of age and degree of facial nerve recovery in patients with Bell's palsy. Eur Arch Otorhinolaryngol 256(10):520-522

20. Khedr E, Abo El-Fetoh N, El-Hammady D, Ghandour AM, Osama K, Zaki AF et al (2018) Prognostic role of neurophysiological testing 3-7 days after onset of acute unilateral Bell's palsy. Neurophysiol Clin 48(2):111-117

21. Mantsopoulos K, Psillas G, Psychogios G, Brase C, Iro H, Constantinidis J (2011) Predicting the long-term outcome after idiopathic facial nerve paralysis. Otol Neurotol 32:848-851

22. Linder T, Abdelkafy W, Cavero-Vanek S (2010) The management of peripheral facial nerve palsy: paresis versus paralysis and sources of ambiguity in study designs. Otol Neurotol 31:319-327

23. Heath J, Cull R, Smith I, Murray JA (1988) The neurophysiological investigation of Bell's palsy and the predictive value of the blink reflex. Clin Otolaryngol Allied Sci 13:85-92

24. Kanaya K, Ushio M, Kondo K, Hagisawa M, Suzukawa K, Yamaguchi T et al (2009) Recovery of facial movement and facial synkinesis in Bell's palsy patients. Otol Neurotol 30:640-644

25. Ozgur A, Semai B, Hidir U, Mehmet Fatih O, Tayfun K, Zeki O (2010) Which electrophysiological measure is appropriate in predicting prognosis of facial paralysis? Clin Neurol Neurosurg 112(10):844-848

26. Takemoto N, Horii A, Sakata Y, Inohara H (2011) Prognostic factors of peripheral facial palsy: multivariate analysis followed by receiver operating characteristic and Kaplan-Meier analyses. Otol Neurotol 32:1031-1036

27. Mikula I, Miskov S, Negovetiae RI (2002) Blink reflex in the prediction of outcome of idiopathic peripheral partial facioparesis: follow-up study. CMJ 43:319-323

28. Hah Y, Kim S, Jung J, Kim SS, Byun JY, Park MS et al (2018) Prognostic value of the blink reflex test in Bell's palsy and Ramsay-hunt syndrome. Auris Nasus Larynx 45(5):966-970

\section{Publisher's Note}

Springer Nature remains neutral with regard to jurisdictional claims in published maps and institutional affiliations.

\section{Submit your manuscript to a SpringerOpen ${ }^{\circ}$ journal and benefit from:}

- Convenient online submission

- Rigorous peer review

- Open access: articles freely available online

- High visibility within the field

- Retaining the copyright to your article

Submit your next manuscript at $\boldsymbol{\nabla}$ springeropen.com 